\title{
Photochemical Behavior of Nifedipine Derivatives and Application to
} Photosensitive Polymers

\section{Tsuguo YAMAOKA, Shoichi YOKOYAMA, Toshihiko OMOTE, Kazuhiko NAITOH} Department of Image Science, Faculty of Engineering, Chiba University 1-33, Yayoi-cho, Inage-ku, Chiba 263

\section{Photoresists based on photosensitivity of nifedipine derivatives}

Nifedipine derivatives are sensitive to the light and converted to o-nitrosophenyl pyridine. ${ }^{1-8)}$ The authors found that novolak resin containing nifedipine derivatives gave alkaline developable positive-working photoresists. ${ }^{7-8)}$ T. Omote et al. reported that poly(amic acid) is sensitized to the near UV light by addition of nifedipine derivatives and the photosensitive poly(amic acid) exhibits the dual-mode property depending on the process after exposure. ${ }^{8)}$ The poly(amic acid) works as a aqueous base developable positive resist similarly to the novolak resin if it is developed with TMAH successively after exposure. On the other hand, if the poly(amic acid) is baked at an appropriate temperature before development, it shows the negative mode where the exposed areas are not soluble in the developer.

2. Photoresist composed of poly(styrene-co-acrylic acid) and nifedipine derivatives. Poly(styrene-co-acrylic acid) containing nifedipine derivatives were found to give a dual-mode photoresist. When this resist material coated on a Si wafer is exposed to $\mathrm{i}$ - or g-line of a mercury lamp and developed with TMAH aqueous solution, the positive patterns are formed. In Figure 1, the characteristic curves of the positive resists consisting of poly(styrene-co-acrylic acid) and NMHP or DNMHP are demonstrated. Several positive-working photoresists composed of poly(styrene-coacrylic acid) and novolak resin and nifedipine derivatives are summarized in Table 1. Among these, the combination of poly(styrene-co-acrylic acid) and DNMHP gives the positive resist with the highest sensitivity of $50 \mathrm{~mJ} / \mathrm{cm}^{2}$.

The resist material having the same composition as that described above gives a negative working behavior, if it is baked at $150^{\circ} \mathrm{C}$ for $10 \mathrm{~min}$ after exposure and then developed with aqueous TMAH. The dissolution rate of this photoresist against the exposure and the successive process is illustrated as in Figure 2. Nifedipine and the derivatives produce pyridine derivatives via the photochemical reaction as follows.

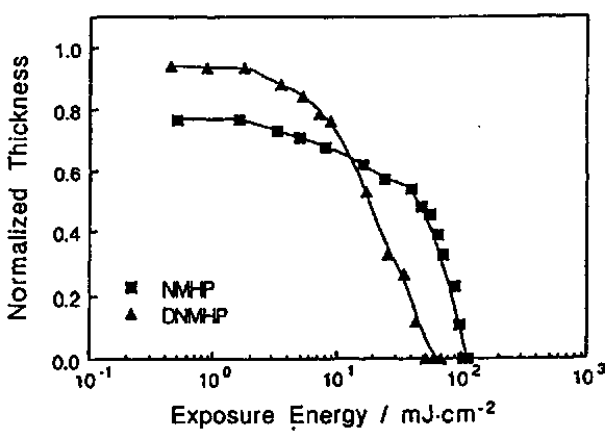

Figure 1

Characteristic curves of the positive(a) and the negative(b) working resists comprising of nifedipine derivative and poly(styrene-co-acrylic acid).

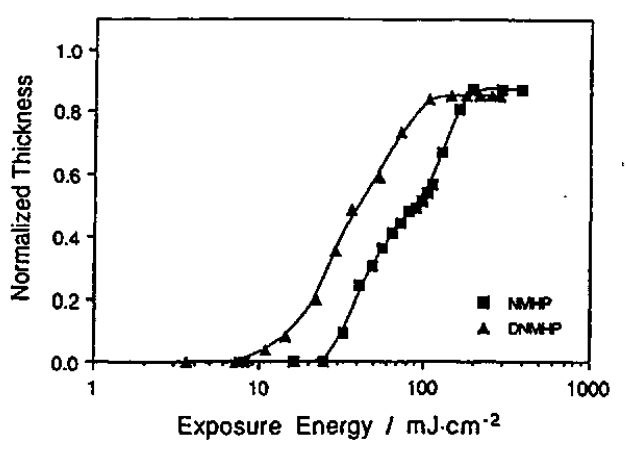

Received June 3, 1994

Accepted June 24, 199.4

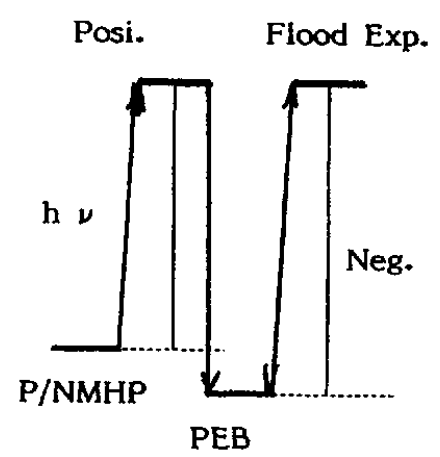

Figure 2

Change of dissolution rate of the resist with exposure and the successive process. 


\section{J. Photopolym. Sci. Technol., Vol.7, No.2, 1994}

Nifedipine derivatives dissolved in poly(styrene-co-acrylic acid) forms hydrogen bonds which cause the solubility inhibition of the polymer in an aqueous base developer. With exposure to the light, nifedipine derivatives is converted to pyridine derivatives and the solubility inhibition is diminished. The difference between the exposed and unexposed areas gives the positive patterns. On the contrary, the mechanism of positive mode may be due to the decarboxylation reaction. It is known that the carboxyl group is decomposed if it is heated in the presence of basic species. Pyridine derivatives produced by the photochemical reaction of nifedipine derivatives are basic and act as the basic catalyst to promote the decarboxylation of poly(styrene-co-acrylic acid). As the result, the polymer is insolubilized in the aqueous base developer. Figure 3 shows the IR spectra of poly(styrene-co-acrylic acid) containing NMHP and the change due to the post exposure bake at $150^{\circ} \mathrm{C}$ for $15 \mathrm{~min}$. The spectrum shows the clear disappearance of the peaks due to $\nu_{\mathrm{c}}$ o of carboxyl group supporting the presumption mentioned above.

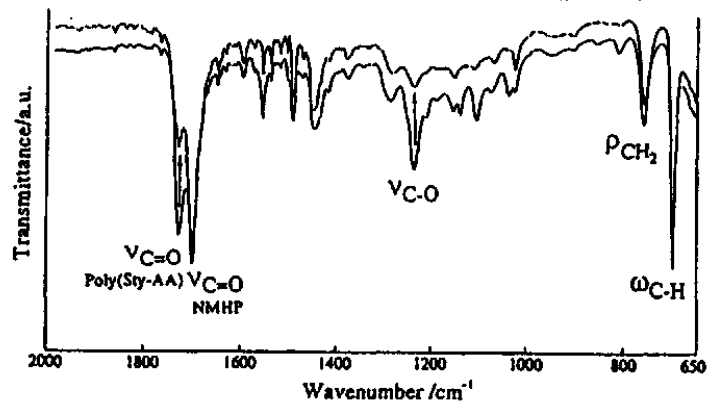

Figure 3

IR spectrum of the photoresist film comprising of poly(styrene -co-acrylic acid) and NMHP, and the change due to exposure and post exposure bake.

3. Photochemical reaction of nifedipine derivatives

The absorption spectra of nifedipine derivative, nitrobenzene and dihydropyridine are shown in Figure 4.
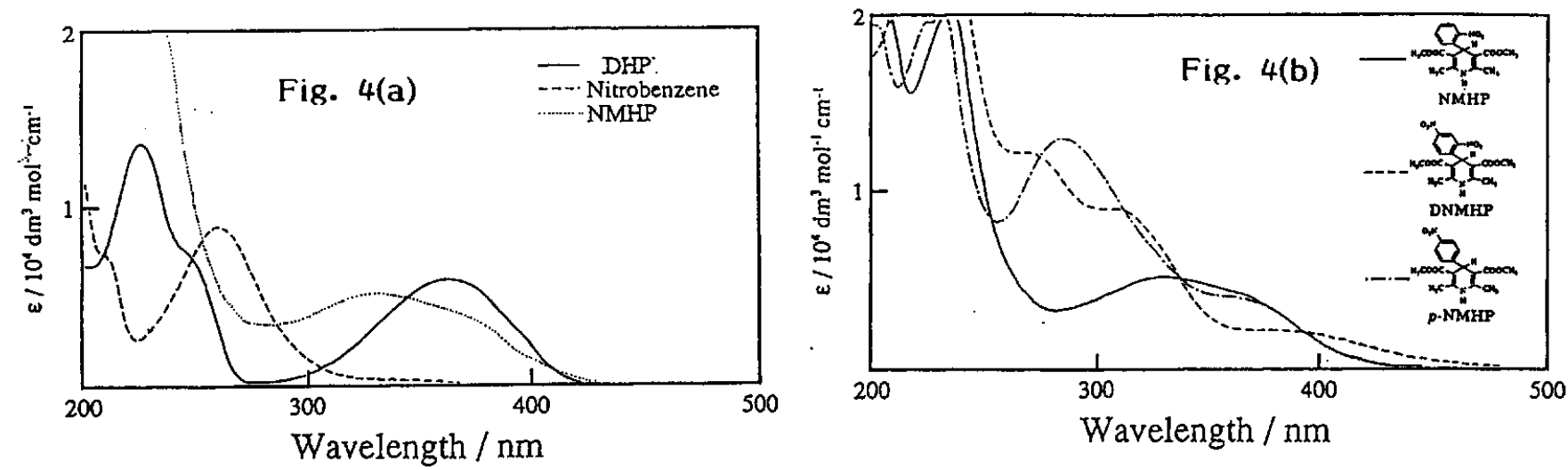

In terms of $\pi$-electronic conjugation system, the electronic spectrum of nifedipine derivative is considered to be almost the superposition of those of nitrobenzene and dihydropyridine. Actually, the absorption spectrum of p-nitrophenyldihydropyridine is almost the simple superposition of nitrobenzene and dihydropyridine. However, the spectrum shown in Figure 4 is not the simple superposition of those for two compounds indicating the existence of some interaction between the moieties corresponding dihydropyridine and nirobenzene.

The quantum yields of photochemical conversion of NMHP, DNMHP and DHP in acetonitrile are summarized in Table 2. Among these, NMHP and DNMHP show the quantum yields with the dependence on the wavelength of exciting light. While the quantum yields are constant regardless the concentration of the solution when excited by $365 \mathrm{~nm}$ light, they are variable depending on the concentration of the solution if excited by $436 \mathrm{~nm}$ light. 
Table 2 Quantum yields of DHP, NMHP and DNMHP in acetonitrile

\begin{tabular}{ccccc}
\hline \multicolumn{2}{c}{ NMHP } & \multicolumn{3}{c}{ DNMHP } \\
\hline $\begin{array}{c}\text { Concentration } \\
(\mathrm{mol} / \mathrm{l})\end{array}$ & 365 & 436 & 365 & 436 \\
\hline $5.0 \times 10^{-4}$ & 0.23 & 0.32 & 0.16 & 0.32 \\
$4.2 \times 10^{-4}$ & & & 0.16 & 0.32 \\
$2.0 \times 10^{-4}$ & 0.23 & 0.18 & 0.14 & 0.26 \\
$4.2 \times 10^{-5}$ & & & 0.13 & 0.23 \\
$2.0 \times 10^{-5}$ & & 0.25 & 0.15 & 0.17 \\
$1.0 \times 10^{-5}$ & 0.22 & & & 0.16 \\
$6.0 \times 10^{-5}$ & & & 0.12 & 0.15 \\
$4.0 \times 10^{-6}$ & & & 0.10 & 0.11 \\
\hline
\end{tabular}

Table 3 Physical data of DHP

\begin{tabular}{|c|c|c|c|c|c|c|c|c|c|}
\hline $\begin{array}{l}\lambda_{\max } \\
(\mathrm{nm})\end{array}$ & $\begin{array}{r}\varepsilon\left(\lambda_{\max }\right) \\
(1 / \mathrm{mol} \cdot \mathrm{cm})\end{array}$ & $\begin{array}{l}{ }^{1} \mathrm{E}_{00} \\
(\mathrm{kcal} / \mathrm{r}\end{array}$ & $\begin{array}{l}{ }^{3} E_{00} \\
n o l)\end{array}$ & $\left(\begin{array}{c}E_{o x} \\
\text { vs } S C E)\end{array}\right.$ & $\Phi$ & $\Phi_{p}$ & $\begin{array}{l}K_{1 s c} \\
\left.10^{10}\right)(x\end{array}$ & $\begin{array}{c}\tau . \\
\left.10^{-9}\right)\end{array}$ & $\left(\times 10^{-6}\right)^{\tau}$ \\
\hline 227 & 26660 & 70.6 & 45.4 & 1.04 & 0.015 & 0.32 & 6.4 & 2.3 & 2.9 \\
\hline 363 & 11390 & & & & & & & & \\
\hline
\end{tabular}

Table 3 summarizes the physical data of DHP. The fluorescence of DHP is quenched by nitro and dinitrobenzene in almost diffusion controlled rate. The values of free energy change $(\Delta \mathrm{G})$ accompanying the electron transfer calculated using the redox potentials for DHP, nitro- and dinitrobenzene predict the possibility of the spontaneous electron transfer from the excited singlet state of DHP to nitro- or dinitrobenzene(Table 4). ${ }^{\text {) }}$

Table 4 The free energy changes ( $\Delta G^{\prime}$ 's) accompanying the electron transfer

\begin{tabular}{lcc}
\hline & $\Delta \mathrm{G}^{\mathrm{s}}(\mathrm{kcal} / \mathrm{mol})$ & $\Delta \mathrm{G}^{\mathrm{T}}(\mathrm{kcal} / \mathrm{mol})$ \\
\hline DHP / Nitrobenzene & -10.02 & 15.18 \\
DHP / 1,3-Dinitrobenzene & -13.11 & 12.09 \\
\hline
\end{tabular}

Inspite of the effective quenching of DHP fluorescence by nitrobenzene, the quantum yields for the conversion of DHP are not increased even in the presence of nitrobenzene or dinitrobenzene. It appears that the photochemical conversion of DHP proceeds independently of the coexisting nitro- or dinitrobenzene. From these observations, 'DHP* may have at least two deactivation paths as expressed by the following schemes.

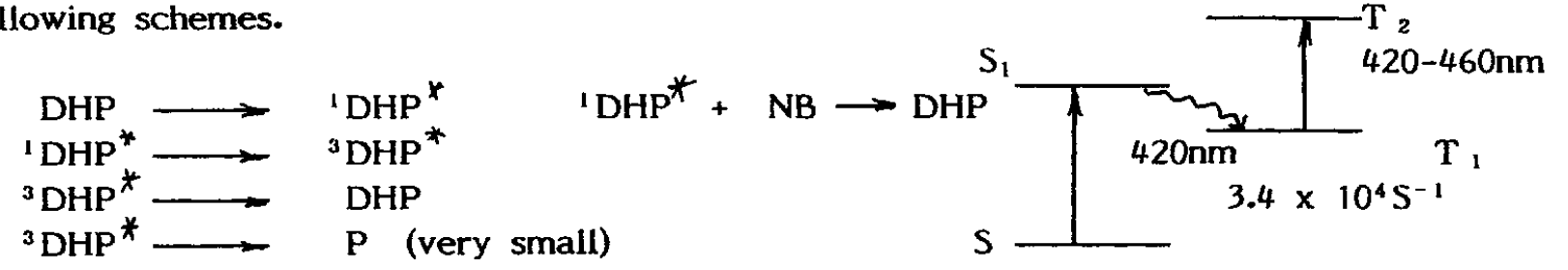


NMHP is more sensitive to light than DHP to convert to the corresponding pyridine derivatives. Based on the observation that the quantum yield is wavelength dependent and the quantum yield with the excitation by $436 \mathrm{~nm}$ light is dependent on the concentration of the solution, the following scheme is proposed for photochemical reaction of NMHP.

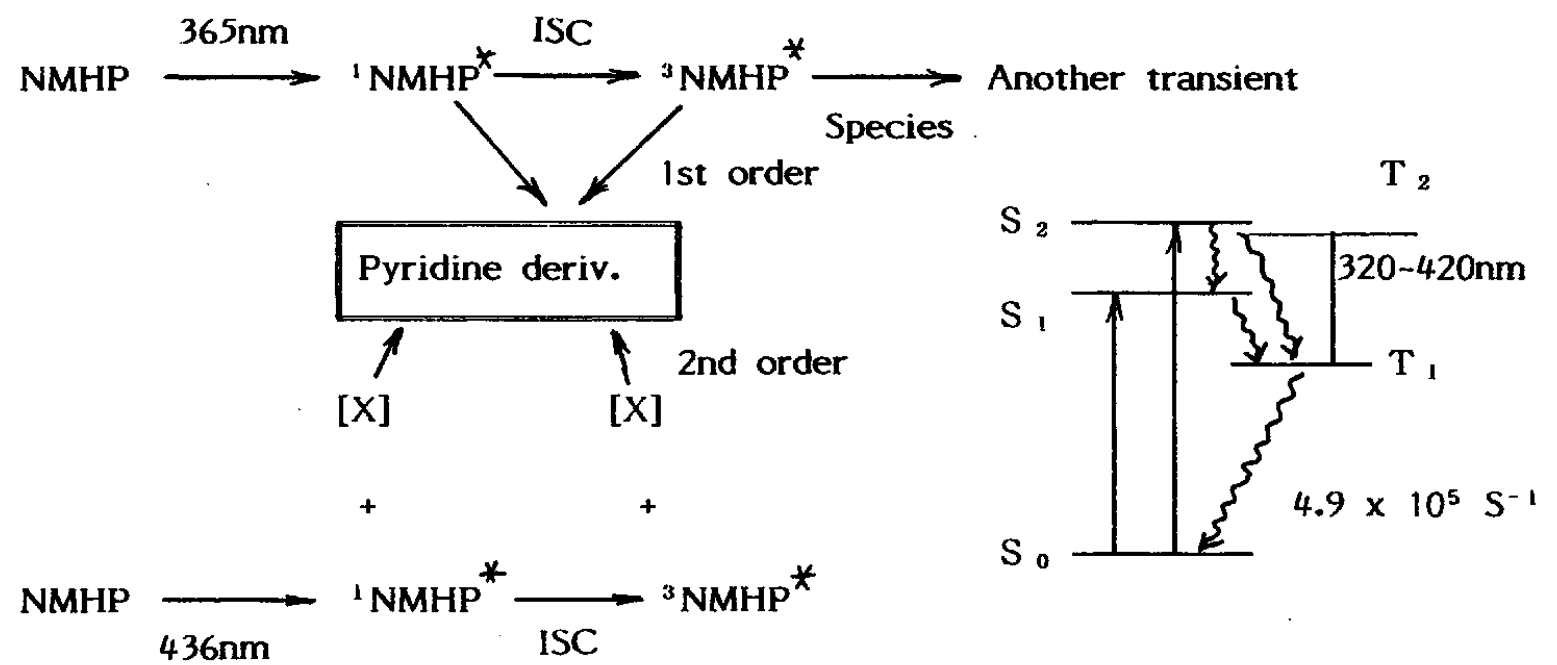

Although NMHP is composed of two molecules, nitrophenybenzene and a dihydropyridine derivative from the standpoint of $\pi$-electronic conjugation, the absorption spectrum of NMHP is different from the simple superposition of those two molecules. It may suggest the delocalization of $\pi$-electronic cojugation between the both moieties. The absorption spectra in Figure 1 show that DHP has the absorption in the longer wavelength region than those of nitro- or dinitrobenzene. If there is some interaction between the both moieties, $\pi$-electronic system can be expressed with the function $\Psi$ based on the electronic configurations shown in Figure 4. The ground state and the lowest and the 2nd lowest excited state are given by Eq.(2), (3) and (4).

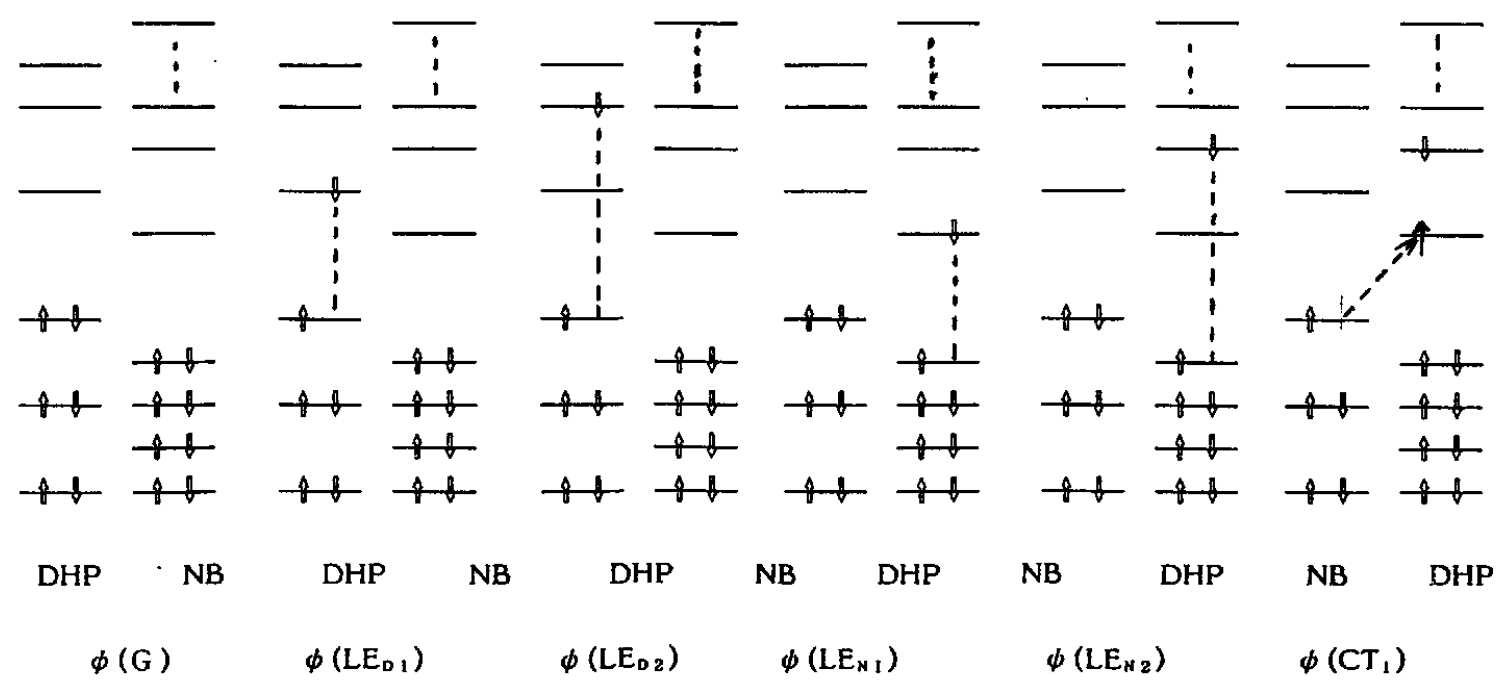

Figure 5 Electronic configurations of the composite molecule comprising of DHP and NB 


$$
\begin{aligned}
& \Psi=c_{1}(G)+c_{2} \phi\left(L_{D_{1}}\right)+c_{3} \phi\left(L_{D_{2}}\right)+c_{4} \phi\left(L_{N_{1}}\right) \\
& +\mathrm{C}_{5} \phi\left(\mathrm{LE}_{\mathrm{N}_{2}}\right)+\mathrm{C}_{6} \phi\left(\mathrm{CT}_{1}\right)+\cdots \\
& \Psi_{G}=c_{G_{1}} \phi(G)+c_{G_{2}} \phi\left(L_{D_{1}}\right)+c_{G_{3}} \phi\left(L_{D_{2}}\right)+c_{G_{4}} \phi\left(L_{N_{1}}\right) \\
& +c_{65} \phi\left(L_{N_{2}}\right)+c_{66} \phi\left(C_{1}\right)+\cdots \\
& \Psi_{1}=c_{11} \phi(G)+c_{12} \phi\left(L_{D_{1}}\right)+c_{13} \phi\left(L_{D_{2}}\right)+c_{14} \phi\left(L_{N_{1}}\right) \\
& +c_{15} \phi\left(\mathrm{LE}_{\mathrm{N} 2}\right)+\mathrm{c}_{16} \phi\left(\mathrm{CT}_{1}\right)+\cdots \\
& \Psi_{2}=\mathrm{c}_{21} \phi(\mathrm{G})+\mathrm{c}_{22} \phi\left(\mathrm{LE}_{\mathrm{D} 1}\right)+\mathrm{c}_{23} \phi\left(\mathrm{LE}_{\mathrm{D} 2}\right)+\mathrm{c}_{24} \phi\left(\mathrm{LE}_{\mathrm{N}_{1}}\right) \\
& +\mathrm{c}_{25} \phi\left(\mathrm{LE}_{\mathrm{N} 2}\right)+\mathrm{c}_{26} \phi\left(\mathrm{CT}_{1}\right)+\cdots
\end{aligned}
$$

Judging from the spectra of NMHP, DHP and nitrobenzene, the approximated functions for the lowest and the 2nd lowest state will be expressed by Eq.(5) and (6). Where, $a$ and $a^{\prime}$ are very small, and $b \gg c, b^{\prime} \ll c^{\prime}$.

$$
\begin{aligned}
& \Psi_{\mathrm{D}}=\mathrm{a} \phi(\mathrm{G})+\mathrm{b} \phi\left(\mathrm{LE}_{\mathrm{D} 1}\right)+\mathrm{c} \phi\left(\mathrm{LE}_{\mathrm{N} 1}\right)+\cdots \cdots \\
& \Psi_{\mathrm{N}}=\mathrm{a}^{\prime} \phi(\mathrm{G})+\mathrm{b}^{\prime} \phi\left(\mathrm{LE}_{\mathrm{D} 1}\right)+\mathrm{c}^{\prime} \phi\left(\mathrm{LE}_{\mathrm{N}_{1}}\right)+\cdots \cdots
\end{aligned}
$$

NMHP excited to $\Psi_{\mathrm{D}}$ or $\Psi_{\mathrm{N}}$ state is mostly contributed by $\mathrm{LE}_{\mathrm{DI}}$ and $\mathrm{LE}_{\mathrm{N} I}$, respectively. In general, NMHP excited to the higher state, $\Psi_{\mathrm{N}}$ may be deactivated to the lowest excited state, $\Psi_{D}$ in the present case, and react at this state. The excitation wavelength dependence of the quantum yield of NMHP, suggests that it reacts directly at $\Psi_{\mathrm{N}}$ state if it is excited by $365 \mathrm{~nm}$ light.

The concentration dependence of the quantum yield is more remarkable for the excitation by $436 \mathrm{~nm}$ than that by $365 \mathrm{~nm}$. The $2 \mathrm{nd}$ order kinetics of the quantum yield of NMHP suggests that the conversion at $\Psi_{\mathrm{D}}$ state is not unimolecular but bimolecular with a mechanism involving the interaction of the excited species on $\Psi_{D}$ state with other excited species on $\Psi_{N}$ such as energy transfer or electron transfer.

\section{Transient spectra of DHP, NMHP and DNMHP.}

Transient species during the photochemical reaction of nifedipine derivatives were observed by a laser flash spectroscopy(Table 5). A transient absorption was observed with DHP at 420,460 and $660 \mathrm{~nm}$. The transient absorption may be due to T-T absorption of DHP which decays with the rate constant of $3.4 \times 10^{-1} \mathrm{~s}^{-1}$.

NMHP shows the transient absorptions at 320 and $420 \mathrm{~nm}$ which are considered as

$\mathrm{T}-\mathrm{T}$ absorption. And as the absorption is decreased, another transient absorption appears at $700 \mathrm{~nm}$ region. The lifetime of $T-T$ absorption is $4.9 \times 10^{5}$. The rate constant of rise curve is $2.4 \times 10^{6}$ and of the decay curve is $2.8 \times 10^{5}$. These values indicate the rise of the 2 nd transient species is faster than the decay rate of $\mathrm{T}$ - $\mathrm{T}$ absorption.

DNMHP shows a transient absorption at $480 \mathrm{~nm}$, the decay rate of which is dependent on the concentration of the solution. The decay rate constants of the transient absorption are $3.5 \times 10^{6}$ for $10^{-3} \mathrm{~mol} / 1$ and $7.8 \times 10^{6}$ for $7 \times 10^{-4} \mathrm{~mol} / 1$, respectively indicating the faster decay rate for the higher concentration of the solution. 
Table 5 Transient absorptions of DHP, NMHP, DNMHP

$\mathrm{T}-\mathrm{T}$ absorption(nm) Decay rate(s ') 2nd transient absorption (s ')

\begin{tabular}{|c|c|c|c|c|c|}
\hline DHP & $420,460,660$ & $2.9 \times 10^{5}$ & $\cdots$ & $\cdots$ & $\ldots \ldots$ \\
\hline NMHP & 320,420 & $4.9 \times 10^{5}$ & $700 \mathrm{~nm}$ & & $\begin{array}{c}2.4 \times 10^{6} \\
2.8 \times 10^{5}\end{array}$ \\
\hline DNMHP & 480 & $\begin{array}{llll}7.8 \times 10^{6} & (\sim 10 \\
3.5 \times 10^{6} & (7 \times 10 \\
\end{array}$ & $\begin{array}{l}\left.{ }^{3} \mathrm{~mol} / \mathrm{l}\right) \\
\left.{ }^{4} \mathrm{~mol} / \mathrm{l}\right)\end{array}$ & & $\cdots \ldots \ldots$ \\
\hline
\end{tabular}

As the results mentioned above, the reaction mechanism for NMHP and DNMHP is proposed as the following schemes.

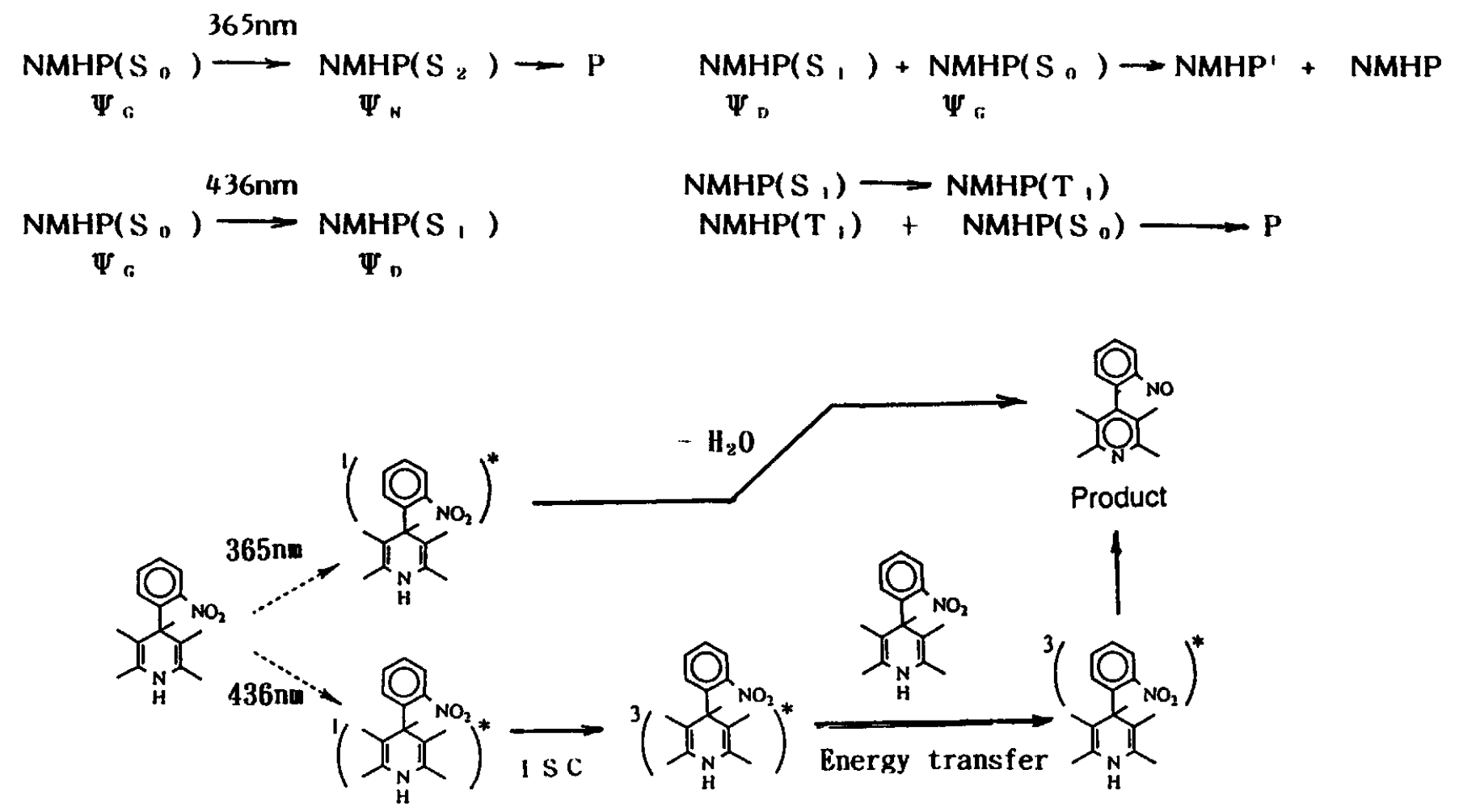

\section{Reference:}

1) R.H.Abeles, R.F.Huton, F.H.Westheimer: J. Am.Chem.Soc., 79, 712(1957)

2) U.K.Pandit: Tetrahedron, 41, 467(1985)

3) D.Ostovic, I.S.H.Lee, R.M.G.Roberts, M.M.Kreevoy: J. Org.Chem., 50,4026(1985)

4) G.A.Hamilton: Prog. Bioorg.Chem., 1,113(1971)

5) A.Ohno, H.Yamamoto, S.Oka: J. Am.Chem.Soc., 103, 2041(1981)

6) G.Deng, H-J.Yu, D.W.Chen: J.Chem.Soc.,Perkin Trans.2,1990.1133

7) T.Yamaoka, H.Watanabe, K.Koseki,T.Asano: J.Imaging Sci., 34, 2050(1990)

8) T.Omote, T.Yamaoka, J.Photopolum.Sci.,Technol., 4, 379(1991)

9) D.Rehm, A.Weller: Isr. J. Chem.,8,259(1970) 